\title{
A MODERNA SOCIEDADE DE RISCO E A CONSTRUÇÃO DA HIDRELÉTRICA DE BELO MONTE
}

Luciana Rosa Rodrigues 1

\section{RESUMO}

As transformações que ocorrem na modernidade, impulsionadas pela globalização e desenvolvimento industrial e tecnológico produzem riquezas, o que geralmente vem acompanhado da produção de riscos. Essas riquezas trazem consigo ameaças incertas, o que gera inquietação na sociedade. O presente trabalho trata do risco na modernidade reflexiva no caso da construção da usina hidrelétrica de Belo Monte, a qual vem sendo feito sob muita polêmica, principalmente pelo dano ambiental que ameaça causar.

Palavras-chave: Risco, modernidade, ambiente

\section{INTRODUÇÃO}

O aumento considerável dos riscos, especialmente os de cunho ambiental, é um ponto chave para o entendimento e transformações que ocorrem na modernidade. Por ser extremamente dinâmica, a sociedade de risco está acabando com a formação de classes e camadas sociais, fazendo com que esse novo estágio de transformação se apresente como algo que destrói e modifica diversas formas sociais, o que Ulrich Beck denomina de modernidade reflexiva.

A "modernização reflexiva" e a globalização, que ganharam impulso especialmente no século XX, trazem consigo grandes mudanças para a sociedade. Essas mudanças ficam muito evidentes no meio ambiente, já que, muitas vezes, a produção de riquezas é acompanhada pela produção de riscos.

Assim, além das fontes de riquezas trazerem consigo ameaças, estas, muitas vezes, são incertas, o que gera inquietações na sociedade. Como exemplo dessa situação, o presente trabalho cita o caso da Usina Hidrelétrica de Belo Monte, a qual vem causando polêmica na medida em que diversos setores da sociedade são contrários à sua construção em razão da falta de conhecimento acerca dos riscos que não estão suficientemente dimensionados, trazendo ainda dúvidas quanto a gestão desses riscos pelo governo, a fim de minimizar ao máximo os efeitos negativos de uma obra desse porte.

\footnotetext{
${ }^{1}$ Advogada e Mestranda em Ciências Sociais pela UFSM. Contato: luli_rosa@hotmail.com
} 


\section{APRESENTAÇÃO}

A proliferação dos riscos, especialmente os ambientais e tecnológicos de graves consequências é um ponto crucial para se entender as características, limites e transformações da modernidade. A multiplicação dos riscos é elemento chave para entender essas transformações, pois a sociedade, produtora de riscos, torna-se cada vez mais reflexiva, o que significa dizer que ela se torna um problema para si própria, ficando mais autocrítica e, ao mesmo tempo em que a humanidade põe a si em perigo, reconhece os riscos que produz e reage diante disso (Jacobi, 2005).

A sociedade moderna, em virtude de seu dinamismo, está acabando com suas formações de classe, camadas sociais, ocupação, papéis dos sexos, família nuclear, agricultura, setores empresariais e com os pré-requisitos e formas contínuas do progresso técnico-econômico, fazendo com que esse estágio de transformação e progresso se apresente como um tipo de modernização que destrói e que modifica as diversas formas sociais, o que se denomina para Ulrich Beck, modernização reflexiva (Guerra, 2009). Essa sociedade "reflexiva" vê-se obrigada a confrontar-se com o que ela mesma criou, de modo que os riscos constituem-se nas incertezas que terão que enfrentar como algo aceitável pelos empreendimentos e novas tecnologias utilizadas, sendo que não há como medir a amplitude desses riscos incertos, não sabendo quem será por eles atingido.

Na modernidade tardia, a produção social de riqueza é acompanhada sistematicamente pela produção social de riscos. A transformação da lógica da distribuição de riqueza na sociedade de escassez para a lógica da distribuição dos riscos está ligada a duas condições: Pela autêntica carência material e pela forças produtivas crescentes no processo de modernização que geram riscos e potenciais de ameaça a níveis até então desconhecidos (Beck, 2010).

Assim, o desenvolvimento passa necessariamente por tais riscos, persistindo as tensões entre desenvolvimento e conservação do meio ambiente, sendo o forte viés economicista um dos fatores de questionamento pelas organizações ambientalistas. $\mathrm{O}$ conceito de desenvolvimento foi objeto de controvérsias e, até recentemente, a abordagem era de ver o desenvolvimento como sinônimo do crescimento econômico (Jacobi, 2005). 
No entanto, a capacidade de evitar riscos é altamente dependente de conhecimento e informação, sendo que, aqui, os meios de comunicação entram em jogo dando visibilidade a esses riscos. Desse modo, estando o tema da sustentabilidade em confronto com o paradigma da sociedade de risco, isso implica na necessidade de se multiplicarem as práticas sociais baseadas no fortalecimento do direito ao acesso à informação e à educação em uma perspectiva integradora (Jacobi, 2005).

Nessa seara:

\begin{abstract}
A história da constituição e das transformações do direito moderno tem sido acompanhada por tentativas recorrentes de pensar as suas relações com outra das instituições centrais da modernidade, a ciência. Essas relações têm conhecido diferentes manifestações, que vão da tentativa de construir o próprio direito numa ciência positiva, à imagem das ciências da natureza que emergiram no século XIX, à apropriação, pela ciência, de procedimentos de apresentação e avaliação dos resultados da investigação científica segundo o modelo da avaliação de provas e de deliberação próprios dos tribunais, passando pelas tentativas de utilizar meios de investigação desenvolvidos pelas ciências para reduzir a incerteza e a subjetividade que, alegadamente, afetariam negativamente a qualidade das decisões judiciais e, consequentemente estariam na origem de injustiças e de erros judiciários (Costa e Nunes, 2001).
\end{abstract}

Esse risco de que Beck trata pode ser claramente identificado na construção da Usina Hidrelétrica de Belo Monte. Considerada a maior e mais cara obra do Plano de Aceleração do Crescimento do governo federal (PAC), sua construção está causando grande polêmica, a medida em que a sociedade está preocupada com os riscos, ou seja, os possíveis impactos ambientais e demais problemas que a construção desse grande empreendimento pode causar.

Dentre diversos outros problemas, principalmente de ordem legal, destacam-se a análises de especialistas, que apontam que estudos do projeto supervalorizam os números sobre o volume real de águas do Xingu, que a seca pode atingir populações indígenas e ribeirinhas que dependem diretamente do rio Xingu para sobreviver, que o aproveitamento hídrico em terras indígenas não está regulamentado em lei, que não há estudos conclusivos acerca do impacto que o alagamento em parte da cidade de Altamira causará, não se sabendo também a quantidade de pessoas que terão que ser removidas, nem onde serão realocadas.

Além disso, especialistas e estudiosos alegam que o "apodrecimento da vegetação que ficar submersa emitirá grandes quantidades de gás metano, que contribui para o 
efeito estufa em até vinte e uma vezes mais que o gás carbônico, e que mais de cem mil pessoas migrarão para a região, sendo que trinta e duas mil permanecerão lá após o fim das obras, o que ocasionará milhares de desempregados. Outro grande problema é que as condições que serão criadas no local propiciarão a proliferação de doenças, como a dengue, leishmaniose, doença de Chagas, febre amarela e principalmente a malária, já que essa é a principal doença em importância epidemiológica da região amazônica. Existe também o problema da diminuição dos peixes, já que em alguns trechos do rio o volume de água será extremamente reduzido, de modo que as condicionantes ao projeto impostas pelo Ibama, incluem que sejam feitos projetos para combater as doenças e permitir que as populações que sobrevivam da pesca tenham alternativas.

Como se observa, são muitos os riscos a que, teoricamente, todos estamos expostos. Isso é corroborado pelo ajuizamento da $14^{\mathrm{a}}$ Ação Civil Pública pelo Ministério Público Federal do Pará (MPF) contra a construção de Belo Monte, onde está sendo discutida uma teoria inédita no direito brasileiro, qual seja, o direito de natureza, o qual refere que não somente a população que reside no local está exposta a riscos, mas um incontável número de pessoas, não tendo como prever o alcance desses riscos, já que neste caso, de acordo com todos os documentos técnicos produzidos, seja pelo Instituto Nacional do Meio Ambiente (Ibama), pelas empreiteiras responsáveis pelos estudos, seja pela Fundação Nacional do Índio (Funai), o Ministério Público Federal ou os cientistas que se debruçaram sobre o projeto, Belo Monte vai causar a morte de parte considerável da biodiversidade na região da Volta Grande do Xingu, pois um trecho de $100 \mathrm{~km}$ do rio terá a vazão bastante reduzida para alimentar as turbinas da hidrelétrica. Esse trecho do Xingu é considerado, por decreto do Ministério do Meio Ambiente (Portaria MMA n 9/2007), como de importância biológica extremamente alta, pela presença de populações animais que só existem nessa área, essenciais para a segurança alimentar e para a economia dos povos da região, de modo que a vazão reduzida vai provocar diminuição de lençóis freáticos, extinção de espécies de peixes, aves e quelônios, a provável destruição da floresta aluvial e a explosão do número de insetos vetores de doenças.

Nesse sentido:

Para o MPF, Belo Monte representa a violação não só dos direitos dos índios, ribeirinhos e agricultores que hoje vivem no Xingu, mas viola o direito da natureza e o direito das gerações futuras ao desenvolvimento sustentável. 
III SEMINÁRID ECDLDGIA

POLÍTICA

E DIREITO NA AMÉRICA LATINA

"Belo Monte expõe o confronto entre o desenvolvimento a qualquer custo e os princípios do direito ambiental. A solução deve ser sempre em favor do último, diante do bem maior a ser preservado, que é a vida em sentido holístico. Belo Monte compromete, de maneira irreversível, a possibilidade das gerações presentes e futuras de atenderem suas próprias necessidades. Apesar de ser um debate novo no judiciário brasileiro, o direito da natureza e das gerações futuras é objeto de pelo menos 14 convenções e tratados internacionais, todos promulgados pelo Brasil, além de estar presente na Constituição Federal (Solte a Gravata.com, 2011).

$\mathrm{O}$ argumento do direito de natureza passa também pela ideia de que os riscos ambientais não estão limitados a um determinado tempo e espaço, podendo acontecer de seus efeitos poderem ser sentidos com maior incidência ao longo dos anos e alcançar vários locais no mundo, fazendo com que tenhamos, de fato, um problema no plano global (Guerra, 2009). Um bom exemplo disso é a emissão de gases poluentes produtores do efeito estufa, que criam um problema de ordem mundial.

Ao longo dos últimos anos, muitas mudanças ocorreram, o que permite, através da tecnologia da intervenção médica, o planejamento de melhoramentos na limpeza da água, no provimento de alimentação suficiente, o que pode ser melhorado com a ajuda da biomedicina (Rose, 2007), de modo que os riscos embora inevitáveis, possam ser previsíveis. Na perspectiva de Mitchel Dean, em certas circunstâncias, o risco pode ser visto como um continuum e neste sentido nunca desaparece completamente. Assim, ele pode ser minimizado, localizado e evitado, mas nunca pode ser dissipado (Areosa, 2008), razão pela qual a gestão desses riscos é fundamental para evitar maiores danos.

Deste modo:

Com efeito, um significado de governança se destaca nesta seara, qual seja, o que remete à ideia de "gestão", inscrito na crença em um consenso inerente à noção de desenvolvimento sustentável. Este consenso aposta na possível conciliação entre os "interesses" econômicos, ecológicos e sociais, abstraindo dessas dimensões as relações de poder que, de fato, permeiam a dinâmica dos processos sociais (Zhouri, 2008).

Em Belo Monte a gestão dos riscos de proliferação de doenças e problema da diminuição de peixes de está sendo feita através de algumas condicionantes ao projeto da hidrelétrica, ou seja, condições impostas pelo Ibama ao consórcio responsável pela obra para que fosse concedida a licença de instalação. Entre algumas das condições, está a reestruturação do atendimento à saúde indígena, e a apresentação de um plano de conservação dos ecossistemas aquáticos, bem como formas de garantia das populações de fauna existentes (Xingu Vivo para Sempre, 2011), o que se constitui em uma forma de biopoder do governo, na tentativa de minimizar os riscos e buscar o desenvolvimento 


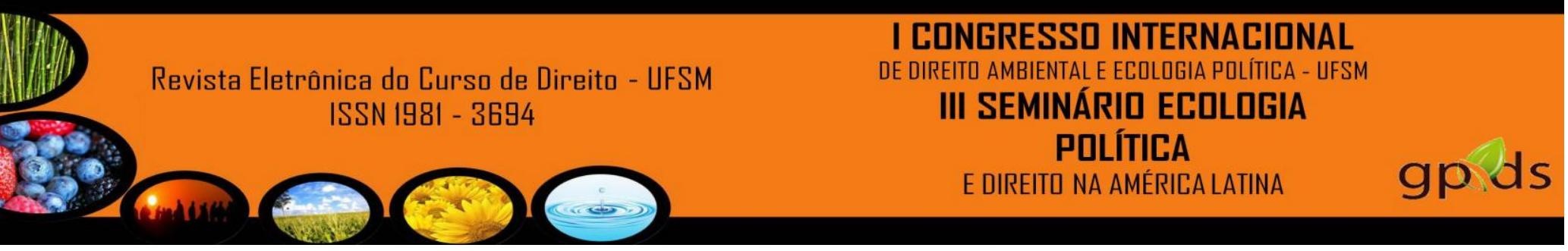

de modo sustentável.

Buscando o desenvolvimento sustentável, em compatibilidade com o progresso cientifico e tecnológico, a precaução apresenta um duplo objetivo: a minimização e gestão dos riscos, bem como a aceitação da inovação. Assim, a lógica precaucionista é inserida num contexto geral de gestão dos riscos, como também na condição de aceitação social dos riscos, cabendo à coletividade distinguir entre as tecnologias que devem ser desenvolvidas e aquelas que devam ser vetadas (Dornelas, 2011).

O risco está em toda parte, fazendo com que prevaleça um grande sentimento de insegurança. Esse sentimento parece ser alimentado pelo desenvolvimento das ciências e das técnicas que são cada vez melhores (Guerra, 2009), pois na medida em que a ciência e tecnologia avançam, trazem consigo o aumento dos riscos, de modo que:

O princípio da precaução pode ser considerado como a forma mais desenvolvida da regra geral, impondo uma obrigação para impedir danos ao meio ambiente. O princípio da precaução faria parte do direito ambiental internacional, sendo o ponto de partida dos avanços e das formulações do direito ambiental nas relações supranacionais, com base no fato de que a grande maioria das convenções internacionais baseia-se no princípio de que a degradação ambiental deve ser impedida - evitando desta forma poluição ou danos - em vez de se esperar que ela ocorra para então, tentar neutralizar seus efeitos negativos. Desta forma, uma vez adotado, há a necessidade da instalação de um sistema de pesquisa que permita fazer a identificação de riscos para o meio ambiente e para a saúde pública. (Kiss apud Dornelas, 2011).

Além dos riscos incertos, há grande revolta da sociedade no que tange ao total descaso do governo federal para com a precaução. Isso fica demonstrado pelo fato de o projeto estar sendo implantado sem o cumprimento legal de suas etapas, visto que os estudos de impacto ambiental foram entregues incompletos ao Ibama, e aceitos por este órgão. Esse fato demonstra que a pressa em realizar a obra não permite que sejam tomadas as devidas precauções para reduzir e/ou, ao menos, conhecer possíveis riscos.

A preocupação com os riscos já não mais está centrada em um perigo que era considerado de origem externa, mas com a própria capacidade dos homens, adquirida ao longo da história, de se autotransformar, de autoconfigurar e de autodestruir as condições de vida, criando novos riscos. Desta forma, as fontes dos perigos não estão na ignorância, mas, sim, no saber, não num domínio da natureza de forma deficiente, mas no seu domínio, nem na falta de ação humana, mas precisamente no sistema de decisões e restrições que se estabeleceu na época industrial. A época moderna é ameaça e promessa de liberação de ameaça que ela mesma criou, e, deste modo, os riscos converteram-se no motor da autopolinização da sociedade industrial moderna (Dormelas, 2011). 

III SEMINÁRII ECDLOGIA

POLÍTICA

E DIREITO NA AMÉRICA LATINA

Belo Monte. Entenda a Polêmica. Disponível em: http://www.slideshare.net/ascomprpa/belo-monte-entenda-a-polmica-6861916, acesso em 17/05/2011.

BLOG Belo Monte Norte Energia. Disponível em: http://www.blogbelomonte.com.br/2011/06/29/plano-de-controle-da-malaria-na-areade-belo-monte-sera-lancado-sexta-feira/, acesso em 12/11/2011.

COSTA, Suzana; NUNES, João Arriscado. As atribulações da ciência "impura": A harmonização da biologia forense e a diversidade dos sistemas jurídicos. Em: Enteados de Galileu? A semiperiferia no sistema no sistema mundial da ciência. Organizadores: João Arriscado Nunes e Maria Eduarda Gonçalves. Edições Afrontamento, Porto, 2001.

DORNELAS, Henrique Lopes. Sociedade de risco e o princípio da precaução: conceito, finalidade e a questão de sua imperatividade. Revista UNIABEU Belford Roxo V.4 Número 6 Jan. - Abr. 2011. Disponível em: http://www.uniabeu.edu.br/publica/index.php/RU/article/view/118. Acesso em $12 / 11 / 2011$.

GUERRA, Sidney. A crise ambiental na sociedade de risco. Lex Humana [21750947] Ano: 2009 Vol: 1 Nr: 2. Disponível em: http://seer.ucp.br/seer/index.php/LexHumana/article/view/27/26. Acesso em 12/11/2011.

JACOBI, Pedro Roberto. Educação ambiental: o desafio da construção de um pensamento crítico, complexo e reflexivo. Educ. Pesqui., São Paulo, v. 31, n. 2, Aug. 2005 Available from<http://www.scielo.br/scielo.php?script=sci_arttext\&pid=S151797022005000200007\&lng=en\&nrm=iso>. access on 10 Nov. 2011. http://dx.doi.org/10.1590/S1517-97022005000200007.

ROSE, N. An emergent form of life? In. ROSE, N. The Politics of life itself: Biomedicine,power and subjectivity in the Twenty-first Century. New Jersey: Princeton University Press, 2007.

SANTOS. Sônia Maria S.B.M. Entrevista realizada pela autora no dia 24/05/2012, na Universidade Federal do Pará.

SOlTE A GRAVATA.COM. Belo Monte: Primeiro Processo do Judiciário brasileiro que aborda o direito de natureza pede paralisação das obras para evitar remoção de índios. Disponível em: http://solteagravata.com/2011/08/19/belo-monteprimeiro-processo-do-judiciario-brasileiro-que-aborda-o-direito-da-natureza-pedeparalisacao-das-obras-para-evitar-remocao-de-indios/. Acesso em: 13/11/2011.

WIMMER, Jeffrey; QUANDT, Thorstem. Theory Review. Living in the risk society An interview with Ulrich Beck. Journalism Studies, Vol. 7, nº 2, 2006. 


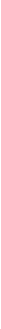

Xingu Vivo para Sempre. Condicionantes do projeto Belo Monte. Disponível em: http://www.xinguvivo.org.br/. Acesso em 26/11/2011. 